\title{
Analisis Keberlanjutan Dimensi Sosial Budaya Usahatani Padi Sawah di Kabupaten Siak Provinsi Riau
}

\author{
Rachmiwati Yusuf ${ }^{1}$, Usman Pato ${ }^{2}$, Usman M. Tang ${ }^{3}$, Rahman Karnila ${ }^{3}$ \\ ${ }^{1}$ Peneliti pada Balai Pengkajian Teknologi Pertanian Riau \\ ${ }^{2}$ Fakultas Pertanian Universitas Riau Kampus Bina Widya Panam KM 12.5 Pekanbaru, Telp. 0761-862620 \\ ${ }^{3}$ Fakultas Perikanan dan Ilmu Kelautan Universitas Riau Kampus Bina Widya Panam KM 12.5 Pekanbaru
}

\begin{abstract}
The study was conducted from January to July 2018 in four sub-districts (Bunga Raya, Sabak Auh, Sungai Apit and Sungai Mandau) in Siak Regency. The sample of farmers in this study were 203 people who were selected by purposive sampling. Data collection was done by interviewing techniques using questionnaires and field observations. The analysis of the sustainability of lowland rice farming was carried out based on the assessment of index and sustainability status using the Rap-Rice method in Multi-Dimensional Scaling (MDS). The purpose of this study was to analyze the index and the status of sustainability of the sociocultural dimensions of wetland farming and analyze the role of each of the socio-cultural attributes that have sensitivity to the management of rice farming in the future. The results of Rap-Rice analysis of the seven socio-cultural attributes analyzed, two attributes provide sensitivity to the District (Bunga Raya, Sabak Auh and Sungai Mandau). Four attributes give sensitivity to Sungai Apit District. The attribute that gives sensitivity to all sub-districts is the attribute of attending training / counseling. Based on socio-cultural conditions, the analysis of wetland rice farming in Siak District showed a fairly sustainable category for Bunga Raya District (56.7\%), Sabak Auh (50.80\%) and Sungai Mandau (51.10\%) while for Sungai Apit Subdistrict the value was obtained (47.70\%) or less sustainable .
\end{abstract}

Key Words: Sustainability analysis, socio-culture, lowland rice farming

Indonesia sebagai Negara yang berdaulat, berkomitmen untuk mewujudkan ketahanan pangan, hal ini tertuang dalam Undang-Undang Nomor 18 Tahun 2012 tentang Pangan dan ditindaklanjuti dengan Peraturan Pemerintah Republik Indonesia Nomor 17 Tahun 2015 tentang ketahanan pangan dan gizi yang mengamanatkan bahwa pemerintah bersama masyarakat bertanggung jawab untuk mewujudkan ketahanan pangan bagi seluruh rakyat. Ketahanan pangan diartikan sebagai kondisi terpenuhinya pangan bagi rumah tangga yang tercermin dari tersedianya pangan yang cukup, baik jumlah maupun mutunya, aman, merata dan terjangkau. Pengalaman telah membuktikan kepada kita bahwa gangguan pada ketahanan pangan seperti meroketnya kenaikan harga beras pada waktu krisis ekonomi 1997/1998, yang berkembang menjadi krisis multidimensi, telah memicu kerawanan sosial yang membahayakan stabilitas ekonomi dan stabilitas Nasional.
Ketersediaan beras di pasaran dalam jumlah yang cukup dan harga terjangkau menjadi pekerjaan rumah yang serius bagi pemerintah. Apabila terjadi kelangkaan komoditas tersebut di pasaran akan menimbulkan kepanikan masyarakat, baik konsumen, industri, maupun pedagang, oleh karena itu pemerintah harus mampu menjamin ketersediaan komoditas ini, hal ini menunjukkan bahwa pengadaan produksi beras dalam negeri sangat penting dalam rangka keberlanjutan kemandirian pangan nasional dengan sasaran tercapainya swasembada pangan/beras (Suryana, 2005).

Keberlanjutan meliputi hal yang kompleks terlebih lagi ketika harus mengintegrasikan berbagai informasi dari aspek ekologi, ekonomi dan sosial budaya (Alder et al., 2003). Terkait dengan pemenuhan kebutuhan manusia Mardikanto (2009) mengemukakan tentang pembangunan berkelanjutan ialah pemanfaatan sumberdaya untuk memenuhi kebutuhan generasi saat ini 
dan yang akan datang dengan tetap memperhatikan keselamatan lingkungan Pertanian berkelanjutan (sustainable agriculture) dibangun dengan pendekatan yang dapat memelihara produksi dan keuntungan pertanian yang tinggi tanpa berakibat pada kerusakan lingkungan, sehingga suatu pembangunan diharapkan selalu berwawasan lingkungan. Pertanian yang berwawasan lingkungan merupakan sistem pertanian yang dapat menciptakan agroekosistem yang optimal dan lestari berkelanjutan secara ekologi, ekonomi dan sosial (Serageldin and Steer, 1994, Sitorus, 2004 dan Liu and Zhang, 2013).

Penentuan indeks keberlanjutan dimensi teknologi padi sawah dan faktor-faktor apa saja yang mempengaruhinya perlu diketahui, untuk mengevaluasi keberlanjutan, agar permasalahan sosial budaya yang menghambat usahatani padi sawah di Kabupaten Siak dapat diatasi secara cepat dan tepat. Tujuan dari penelitian ini adalah untuk menganalisis indeks dan status keberlanjutan dimensi sosial budaya padi sawah dan menganalisis peran masing-masing atribut yang mempunyai sensitivitas terhadap pengelolaan usahatani padi sawah di dimasa yang akan datang.

\section{BAHAN DAN METODE}

\section{Waktu dan Tempat}

Penelitian ini telah dilaksanakan selama tujuh bulan, mulai dari bulan Januari sampai dengan bulan Juli 2018. Bertempat di Kabupaten Siak pada empat Kecamatan sentra padi sawah yaitu, Kecamatan Bunga Raya, Sabak Auh, Sungai Apit dan Sungai Mandau.

\section{Jenis dan Sumber Data}

Jenis data dalam penelitian ini dikelompokan menjadi dua yaitu data primer dan data sekunder. Data primer diperoleh melalui pengamatan langsung di lapangan (observasi) dan hasil wawancara mendalam dari 203 petani dan 20 stakeholders. Informan dipilih menggunakan purposive sampling dan identifikasi stakeholders dilakukan dengan metode snowball sampling yaitu stakeholders merekomendasikan stakeholders lainnya sebagai responden (Wildemuth, 2009).
Penentuan sampel petani dihitung menggunakan persamaan Slovin dalam Ryan (2013) dengan margin error 7\%. Data sekunder diperoleh dari dokumen yang dipublikasikan oleh Pemerintah Kabupaten Siak, Dinas Pertanian Siak dan Badan Pusat Statistik (BPS) Kabupaten Siak baik berupa profil kecamatan, monografi, buku sensus pertanian, laporan hasil penelitian dan dokumen lainnya mengenai peraturan perundang-undangan, tupoksi serta rencana strategis pengelolaan yang dimiliki oleh setiap instansi yang terkait.

\section{Metode Analisis}

Status keberlanjutan dimensi teknologi padi sawah dinyatakan dalam bentuk indeks keberlanjutan berdasarkan pendekatan Rap-rice dengan menerapkan teknik MDS (Multi Dimensional Scaling) (Kavanagh, 2001 and Fisheries, 2002). Pendekatan Rap-rice dimodifikasi dari program Rapfish (Rapid Assessment Techniques for Fisheries) yang dikembangkan oleh Fisheries Center, University of British Columbia (Fauzi dan Anna, 2005). Metode MDS merupakan teknik analisis statistik yang mentransformasi setiap dimensi dan multidimensi pada dimensi keberlanjutan usahatani padi sawah (Rao and Rogers, 2006). Menurut Nurmalina (2008), teknik MDS memetakan dua titik atau objek yang sama dalam satu titik yang saling berdekatan, sebaliknya obyek atau titik yang berbeda digambarkan dengan titik-titik yang berjauhan. Multi Dimensional Scaling adalah kumpulan teknik statistik untuk menganalisis kemiripan dan ketidakmiripan antar objek, memberikan hasil yang berupa plot titik-titik sehingga jarak antar titik menggambakan tingkat kemiripan atau ketidakmiripan dan memberikan petunjuk untuk mengidentifikasi peubah tak diketahui atau faktor yang mempengaruhi munculnya kemiripan atau ketidakmiripan (Kavanagh, 2001).

Analisis ordinasi Rap-Rice dilakukan dengan tahapan (1) penentuan atribut; (2) penilaian setiap atribut dalam skala ordinal (scoring); (3) analisis ordinasi Rap-Rice untuk menentukan ordinasi dan nilai stress melalui ALSCAL Algoritm; (4) melakukan rotasi untuk menentukan posisi indeks dan status keberlanjutan pengelolaan usahatani padi pada ordinasi baik dan buruk; (5) melakukan analisis 
sensitivitas (leverage analysis) dan monte carlo analysis. Indikator keberlanjutan adalah alat yang digunakan untuk memberikan informasi secara langsung atau tidak langsung mengenai viabilitas sebuah sistem di masa mendatang dari berbagai level tujuan, dimana penggunaan dianggap penting karena menjadi informasi bagi perencanaan dan pengembangan sistem selanjutnya. Nilai stress $<25 \%$ merupakan nilai stress yang dapat diterima.

Metode penentuan indeks keberlanjutan usahatani padi sawah dengan teknik Rapfish dilakukan berdasarkan sistematika yang telah ditentukan. Menurut Nababan et al. (2008) penentuan Indeks dan status keberlanjutan berdasarkan tahapan: 1) pengkajian atributatribut pada setiap dimensi keberlanjutan dan menilai atribut tersebut berdasarkan data aktual melalui pengamatan lapangan, wawancara bersama pakar, dan kajian pustaka, 2) nilai skor atribut-atribut setiap dimensi keberlanjutan kemudian dianalisis pada program Microsoft Excell dengan menggunakan template yang telah disiapkan sebelumnya, sehingga diperoleh suatu besaran nilai yang dikenal dengan indeks keberlanjutan, 3) mengkategorikan nilai indeks keberlanjutan berdasarkan selang keberlanjutan untuk memperoleh status keberlanjutan. Selang nilai skor keberlanjutan setiap dimensi, antara lain: buruk $(0,00-25,00)$, kurang (25,01-50,00), cukup $(50,01-75,00)$, dan baik $(75,01-100,00)$. Hasil lain yang diperoleh dalam analisis MDS adalah penentuan faktor pengungkit (leverage factors) yang merupakan faktor-faktor strategis pengelolaan usahatani padi sawah di masa depan (Pitcher and Preikshot, 2001).

\section{HASIL}

Indeks dan status keberlanjutan dimensi sosial budaya pengelolaan padi sawah di Kabupaten Siak ditentukan berdasarkan hasil penelitian dan wawancara dengan petani di Kabupaten Siak. Atribut yang memiliki sensitivitas terhadap status keberlanjutan diketahui dengan melakukan analisis leverage. Analisis leverage dilakukan untuk mengetahui atribut yang sensitif terhadap keberlanjutan pengelolaan usahatani padi sawah. Atribut yang diperkirakan memberi pengaruh terhadap dimensi ini adalah tingkat pendidikan, motivasi petani bertani, mengikuti pelatihan pertanian, status kepemilikan lahan, umur petani, pengalaman dalam berusahatani dan frekuensi konflik berkaitan dengan usahatani. Nilai indeks semua atribut disajikan pada (Tabel 1) dan status keberlanjutan dimensi sosial budaya pengelolaan usahatani padi sawah dapat dilihat pada (Gambar 1). Atribut sensitif yang memberikan pengaruh terhadap nilai indeks keberlanjutan dimensi sosial dan budaya dapat diketahui dari analisis leverage (Gambar 2). Kemampuan setiap atribut untuk menjelaskan dan memberikan kontribusi terhadap keberlanjutan sistem yang dikaji dapat diketahui dengan melihat nilai koefisien $\left(\mathrm{R}^{2}\right)$ setiap dimensi yang dianalisis. Nilai stress dan koefisien determinasi dimensi teknologi disajikan pada Tabel 2. 
Tabel 1. Nilai skor dimensi sosial-budaya dan atribut keberlanjutan pengelolaan usaha tani padi sawah pada empat kecamatan di Kabupaten Siak

\begin{tabular}{|c|c|c|c|c|c|c|c|c|}
\hline \multirow[b]{2}{*}{ No. } & \multicolumn{4}{|c|}{ Status } & \multicolumn{4}{|c|}{ Skor } \\
\hline & Atribut & Baik & Buruk & Keterangan & $\mathrm{BR}$ & $\begin{array}{c}\text { S.A } \\
\mathrm{u}\end{array}$ & $\begin{array}{c}\text { S.A } \\
\text { p }\end{array}$ & $\begin{array}{l}\text { S. } \\
\text { M }\end{array}$ \\
\hline 1 & $\begin{array}{l}\text { Tingkat } \\
\text { pendidikan } \\
\text { (Rapfish; } \\
\text { Tesfamichael dan } \\
\text { Pitcher, 2006) }\end{array}$ & 3 & 0 & $\begin{array}{l}\text { (0) SD } \\
\text { (1) SMP } \\
\text { (2) SMA } \\
\text { (3) Perguruan } \\
\text { Tinggi }\end{array}$ & 0 & 0 & 0 & 0 \\
\hline 2 & $\begin{array}{l}\text { Motivasi petani } \\
\text { bertani (Rapfish; } \\
\text { Tesfamichael dan } \\
\text { Pitcher, 2006) }\end{array}$ & 2 & 0 & $\begin{array}{l}\text { (0) Meneruskan } \\
\text { tradisi } \\
\text { (1) Pendapatan } \\
\text { tambahan } \\
\text { (2) Pendapatan } \\
\text { utama }\end{array}$ & 2 & 1 & 1 & 1 \\
\hline 3 & $\begin{array}{l}\text { Mengikuti } \\
\text { pelatihan } \\
\text { pertanian/penyulu } \\
\text { han } \\
\text { (Abdollahzadeh et } \\
\text { al., 2015) }\end{array}$ & 4 & 0 & $\begin{array}{l}\text { (0) Tidak pernah } \\
\text { (1) } 1 \mathrm{x} / \text { tahun } \\
\text { (2) } 2 \mathrm{x} / \text { tahun } \\
\text { (3) } 3 \mathrm{x} / \text { tahun } \\
\text { (4) }>3 \mathrm{x} / \text { tahun }\end{array}$ & 2 & 1 & 1 & 1 \\
\hline 4 & $\begin{array}{l}\text { Status } \\
\text { kepemilikan lahan } \\
\text { (Mudakir, 2011) }\end{array}$ & 3 & 0 & $\begin{array}{l}\text { (0) Bagi hasil } \\
\text { (1) Sewa } \\
\text { (2) Milik Sendiri } \\
\text { (3) Milik Desa }\end{array}$ & 2 & 2 & 2 & 3 \\
\hline 5 & $\begin{array}{l}\text { Umur petani } \\
\text { (Sunaryo, 2006) }\end{array}$ & 3 & 0 & $\begin{array}{l}\text { (0) }<25 \text { tahun } \\
\text { (1) }>55 \text { tahun } \\
\text { (2) }>40-55 \text { tahun } \\
\text { (3) } 25-40 \text { tahun }\end{array}$ & 2 & 2 & 2 & 2 \\
\hline 6 & $\begin{array}{l}\text { Pengalaman } \\
\text { dalam } \\
\text { berusahatani } \\
\text { (Andayani dan } \\
\text { Sanira, 2015) }\end{array}$ & 3 & 0 & $\begin{array}{l}\text { (0) }<10 \text { tahun } \\
\text { (1) } 10-15 \text { tahun } \\
\text { (2) } 15-20 \text { tahun } \\
\text { (3) }>20 \text { tahun }\end{array}$ & 2 & 1 & 1 & 1 \\
\hline 7 & $\begin{array}{l}\text { Frekwensi konflik } \\
\text { berkaitan denngan } \\
\text { usahatani } \\
\text { (Rapfish; } \\
\text { Tesfamichael dan } \\
\text { Pitcher, 2006) }\end{array}$ & 2 & 0 & $\begin{array}{l}\text { (0) } \geq 3 x \text { setahun } \\
\text { (1) } 1-2 x \text { setahun } \\
\text { (2) Tidak pernah }\end{array}$ & 1 & 1 & 1 & 1 \\
\hline
\end{tabular}

Ket : BR (Bunga Raya), SAu (Sabak Auh), SAp (Sungai Apit), SM (Sungai Mandau) 



Gambar 1. Indeks keberlanjutan dimensi sosial budaya pada empat kecamatan di Kabupaten Siak

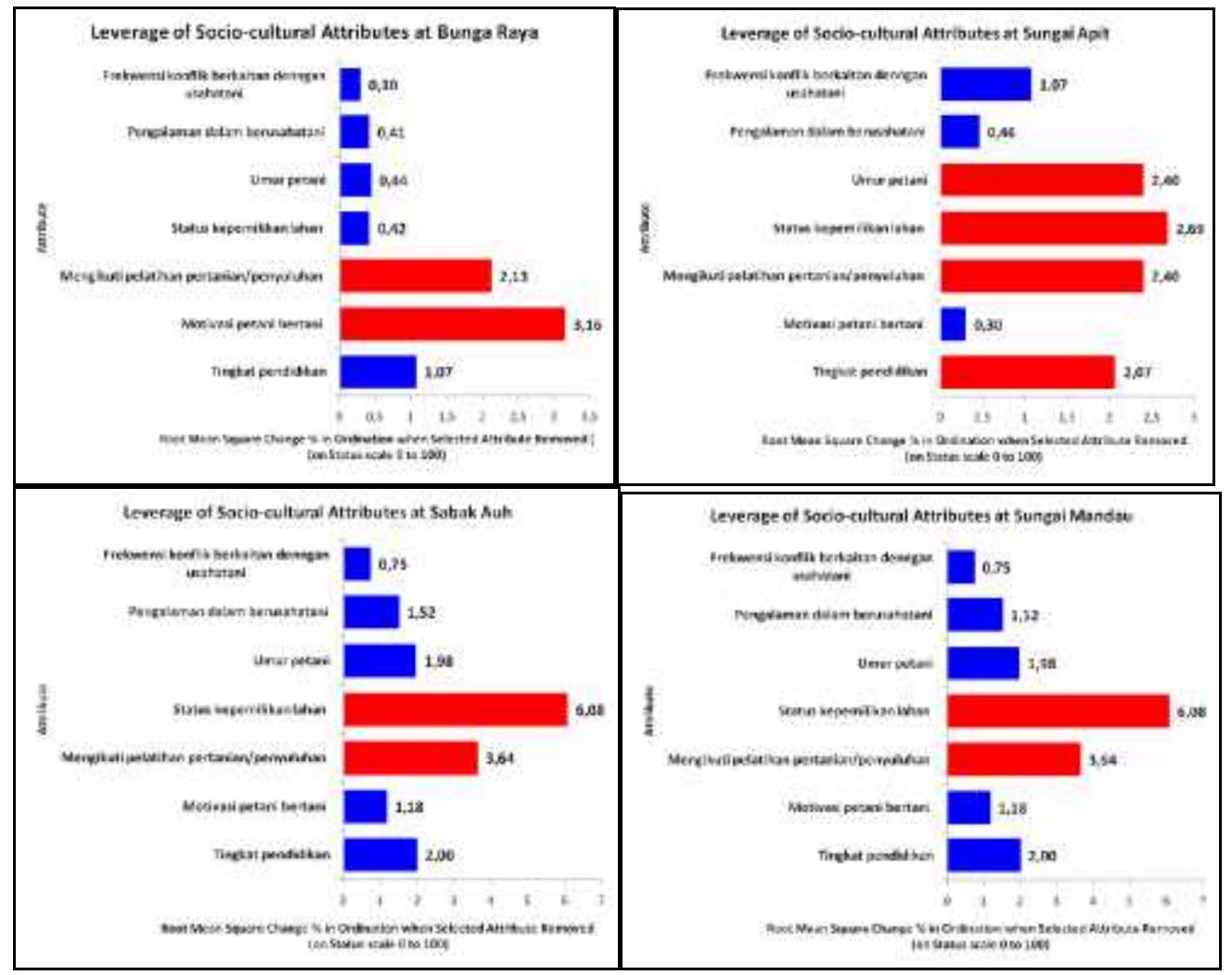

Keterangan : atribut sensitif, atribut tidak sensitive

Gambar 2. Peran masing-masing atribut dimensi sosial dan budaya pada empat kecamatan di Kabupaten Siak yang dinyatakan dalam bentuk nilai RMS (Root Means Square). 
Tabel 2. Nilai stress, koefisien determinasi dan pengaruh galat dimensi teknologi

\begin{tabular}{lccccc}
\hline Kecamatan & $\begin{array}{c}\text { Indeks } \\
\text { Keberlanjutan } \\
\text { (MDS) }\end{array}$ & Stress & $\mathrm{R}^{2}$ & $\begin{array}{c}\text { Analisis } \\
\text { MonteCarlo* }\end{array}$ & $\begin{array}{c}\text { Perbedaan } \\
\text { (MDS-MC) }\end{array}$ \\
\hline Bunga Raya & 56,70 & 0,15 & 0,94 & 56,50 & 0,20 \\
Sabak Auh & 50,80 & 0,15 & 0,94 & 50,80 & 0,30 \\
Sungai Apit & 47,70 & 0,15 & 0,94 & 47,70 & 0,70 \\
Sungai & 51,10 & 0,14 & 0,94 & 51,10 & 0,10 \\
Mandau & & & & \\
\hline
\end{tabular}

Keterangan :

*Galat pada taraf kepercayaan $95 \%$

Nilai indeks 25,01-50,00 dikategorikan kurang berkelanjutan Nilai indeks 50,01-75,00 dikategorikan cukup berkelanjutan Nilai stress $<0,25$ berarti goodness of fit

Nilai $\mathrm{R}^{2}>80 \%$ atau mendekati $100 \%$, kontribusi sangat baik

\section{PEMBAHASAN}

Indeks dan status keberlanjutan dimensi sosial budaya pengelolaan usahtani padi sawah

Hasil pengolahan data dari Tabel 1 dan analisis data pada Gambar 1 menunjukkan nilai indek keberlanjutan dimensi sosial dan budaya untuk Kecamatan Bunga Raya 56,70\%, Sungai Mandau 51,10 dan Sabak Auh 50,80\%\%, artinya status dimensi ini cukup berkelanjutan (>50\%). Nilai indeks keberlanjutan Kecamatan Sungai Apit adalah $(47,7 \%)$ atau kurang berkelanjutan $(<50 \%)$. Pengelolaan usahatani padi sawah di Kecamatan Sungai Apit belum memberikan dukungan terhadap pembangunan dimensi sosial dan budaya, sementara di Kecamatan Bunga Raya, Sabak Auh dan Sungai Mandau pengelolaan usahatani padi sawah sudah dapat memberikan dukungan terhadap pembangunan dimensi sosial dan budaya. Dalam upaya mengoptimalkan keberlanjutan usahatani padi sawah di Sungai Apit maka pembangunan dimensi sosial dan budaya penting diperhatikan dan ditingkatkan.

Berdasarkan analisis leverage pada Gambar 2, diperoleh dua atribut sensitif terhadap nilai indeks keberlanjutan dimensi sosial dan budaya untuk Kecamatan Bunga Raya, Sabak Auh dan Sungai Mandau serta empat atribut sensitif untuk Kecamatan Sungai Apit. Atribut mengikuti pelatihan/penyuluhan memberikan sensitifitas yang cukup tinggi untuk semua kecamatan. Artinya atribut pelatihan/penyuluhan sangat penting diperhatikan dalam rangka mempertahankan keberlanjutan usahatani padi sawah di
Kabupaten Siak. Melalui pelatihan/ penyuluhan petani menjadi tahu, mengerti dan paham bagaimana cara bercocok tanam yang baik, kapan waktu panen yang tepat, alat panen apa yang dapat digunakan untuk menekan tingkat kehilangan hasil, faktor-faktor apa saja yang harus diperhatikan agar keberlanjutan usahatani tetap dapat dipertahankan.

Peningkatan pengetahuan petani yang diaplikasikan dalam usahataninya diharapkan dapat meningkatkan produksi dan produktifitas yang selanjutnya dapat membantu petani memperbaiki mutu hidup dan kesejahteraannya. Pembinaan masyarakat tani dalam berusahatani dengan mengadakan pelatihan untuk merubah pola pikir, perilaku dan kegiatan yang memiliki pedoman yang jelas sangat berpengaruh terhadap keberlanjutan usahatani padi. Hal ini sesuai dengan yang disampaikan oleh (Timprasert et al., 2014; Okonya and Kroschel, 2016) yang menyatakan bahwa pelatihan/penyuluhan diperlukan untuk meningkatkan pengetahuan petani misalnya dalam menerapkan pengelolaan hama terpadu dan budidaya tanaman. Pernyataan ini di perkuat dengan hasil penelitian (Vildan et al., 2009; Harahap et al., 2013 dan Kuntariningsih et al., 2013) yang menyatakan pelatihan/penyuluhan dapat menurunkan biaya produksi, berpengaruh singifikan terhadap peningkatan produktivitas dan pendapatan petani hingga $40 \%$.

Hasil penelitian diketahui bahwa pelatihan memiliki dampak yang positif bagi usahatani jangka panjang karena dapat meningkatkan keahlian, ketrampilan, maupun penyelesaian setiap permasalahan dalam usahatani padi yang 
mereka lakukan. Pelatihan menjadi salah satu investasi petani dalam rangka peningkatan sumber daya manusia serta meningkatkan animo petani dalam berusahatani. Hal senada juga dinyatakan Kandaou (2010) yang menyatakan bahwa pelatihan berguna untuk menambah dan meningkatkan pengetahuan/keterampilan serta merubah sikap/perilaku seseorang ke arah yang lebih produktif.

Atribut motivasi petani bertani hanya sensitif untuk Kecamatan Bunga Raya, hal ini disebabkan karena usahatani padi sawah di Bunga Raya merupakan pendapatan utama dalam memenuhi kebutuhan hidup petani. Motivasi petani yang begitu besar juga disebabkan karena adanya dukungan dari pemerintah setempat yang membantu petani dalam menyediakan sarana dan prasarana pendukung seperti perbaikan saluran irigasi, perbaikan jalan usahatani, pengadaan pompa air, pemberian pelatihan/penyuluhan dan sebagainya. Hasil penelitian ini sejalan dengan penelitian yang dilakukan oleh Kandaou (2010) dan Shinta (2011) yang menyatakan bahwa pelatihan/penyuluhan akan mempengaruhi motivasi seseorang untuk bekerja dan berusaha lebih serius, baik dari sisi kreatifitas maupun produktivitas terhadap diri sendiri atau lingkungan.

Pelatihan/ penyuluhan merupakan salah satu pendidikan non formal yang berguna untuk meningkatkan kemampuan petani dalam bidang usahatani padi. Petani yang sering mengikuti pelatihan/penyuluhan terbukti memiliki pola pikir yang lebih terbuka sehingga mereka lebih mudah mengatasi setiap permasalahan yang ada saat melakukan usahatani padi. Pelatihan/ penyuluhan dalam bidang pertanian memiliki manfaat dalam pemberian informasi mengenai inovasi-inovasi baru dalam bidang pertanian dan meningkatkan insentif serta kondisi yang kondusif agar petani mampu memanfaatkan sumber permodalan maupun sumber daya lainnya secara optimal.

Tingkat pendidikan formal dan umur petani memberikan sensitifitas yang tinggi pada Kecamatan Sungai Apit. Pendidikan akan mempengaruhi sikap dan kemampuan petani dalam mengadopsi suatu teknologi, semakin tinggi suatu pendidikan petani maka semakin tinggi pula tingkat adopsinya, untuk itu pembangunan sumberdaya manusia melalui kebijakan pendidikan formal perlu ditingkatkan, sehingga tingkat pendidikan formal petani lebih baik. Pengembangan sumberdaya manusia dapa dilakukan melalui penguatan pelatihan/ penyuluhan atau pendidikan non formal, sehingga tingkat pengetahuan petani tentang lingkungan akan semakin baik. Menurut Hermawan (2005); Dewi et al. (2016) serta Rukka dan Wahab, (2013), terdapat hubungan positif antara tingkat pendidikan dengan perilaku menjaga kelestarian lingkungan.

Hasil penelitian di Sungai Apit menunjukkan $87 \%$ petani responden termasuk ke dalam umur produktif. Responden yang termasuk dalam umur produktif memiliki kelebihan dalam kemampuan fisik yang optimal dan memiliki respon yang baik terhadap inovasi. sedangkan untuk umur tidak produktif mulai mengalami pelemahan dalam kemampuan fisik, sehingga mereka kurang mampu bekerja secara optimal. Hal ini sesuai dengan pernyataan Sunaryo (2006) yang menyatakan salah satu indikator dalam menentukan produktivitas kerja dalam melakukan pengembangan usaha adalah tingkat umur, dimana umur petani yang berusia relatif muda lebih kuat bekerja, cekatan, mudah menerima inovasi baru, tanggap terhadap lingkungan sekitar bila dibandingkan tenaga kerja yang sudah memiliki usia tua.

Atribut status kepemilikan lahan, memberikan sensitifitas untuk Kecamatan Sabak Auh, Sungai Apit dan Sungai Mandau. Kepemilikan lahan umumnya merupakan milik sendiri, hanya Kecamatan Sungai Mandau yang merupakan milik desa, petani hanya mempunyai hak pakai bukan hak milik. Petani tidak berhak menjual belikan tanah tersebut dan tidak boleh memindahtangankan keorang lain tanpa sepengatahuan aparat desa. Petani hanya diberi izin untuk mengelolah lahan jika digunakan untuk menanam padi, palawijah, sayur-sayuran dan tanaman semusim lainnya, sehingga atribut kepemilikan lahan di Kecamatan ini memberikan sensitivitas paling tinggi dibandingkan dengan kecamatan lainnya. Berdasarkan uraian tersebut maka untuk meningkatkan keberlanjutan dimensi sosial budaya usahatani padi sawah, perlu memberikan perhatian serius terhadap atribut sensitif. 


\section{Nilai Stress,Koefisien Determinasi Pengaruh Galat Dimensi Teknologi}

Nilai stress berkisar antara 0,14-0,15 dengan nilai $\mathrm{R}^{2}$ 0,95 (Tabel 2). Dalam Rapfish nilai stress dikatakan baik apabila nilainya di bawah 0,25. Kavanagh (2001) menyebutkan bahwa nilai stress yang dapat ditolerir adalah $<20 \%$, dengan demikian model dapat diterima dengan baik dengan nilai stress sekitar $15 \%$.

Hasil uji ketepatan (goodness of fit) juga menunjukkan bahwa model pendugaan indeks keberlanjutan ekologi dapat digunakan, dimana diperoleh nilai Squared Correlation $\left(\mathrm{R}^{2}\right)$ adalah 0,94 atau mendekati 1 . Nilai R-square semakin mendekati 1 berarti data yang ada semakin terpetakan dengan sempurna. Nilai tersebut menggambarkan bahwa 94-95\% model dapat dijelaskan dengan baik dan sisanya 4-5\% dijelaskan oleh faktor lain. Kavanagh (2001) menyebutkan bahwa nilai Squared Correlation $\left(\mathrm{R}^{2}\right)$ lebih dari $80 \%$ menunjukkan bahwa model pendugaan indeks keberlanjutan baik dan memadai digunakan.

Tabel 2 juga memperlihatkan bahwa tidak ada perbedaan yang nyata nilai indeks MDS dengan hasil analisis Monte Carlo, baik pada nilai sebaran maupun pengaruh galat pada taraf 95\%. Dapat dipastikan bahwa kesalahan pembuatan skor, pengaruh variasi skor, stabilitas proses analisis MDS yang berulangulang maupun kesalahan pemasukan atau hilangnya data tidak memberikan pengaruh. Menurut kavanagh and Pitcher (2004) bahwa analisis Monte Carlo dapat digunakan sebagai metode simulasi untuk mengevaluasi dampak kesalahan acak/galat (random error) dalam analisis statistik.

Hasil analisis Rap-Rice tersebut dapat diterima mengingat hasil uji validasi diperoleh selisih nilai indeks keberlanjutan teknologi dengan nilai Monte Carlo sebesar 0,10 sampai 0,70. Hal ini memberikan selisih perbedaan yang sangat kecil (kurang dari 5). Nilai tersebut menunjukkan pengarug galat (error) atau dampak dari kesalahan pemberian skor relatif kecil. Artinya model Rap-Rice untuk pengelolaan padi sawah dinyatakan memadai sebagai penduga nilai indeks keberlanjutan. Menurut kavanagh and Pitcher (2004), apabila selisih nilai Analisis Rap dikurang Analisis Monte Carlo > 5, maka hasil analisis tidak memadai sebagai penduga nilai indeks keberlanjutan dan apabila selisih nilai kedua analisis tersebut $<5$, maka hasil analisis dianggap memadai untuk menduga nilai indeks keberlanjutan.

\section{SIMPULAN}

Hasil dari penelitian ini dapat disimpulkan bahwa berdasarkan kondisi sosial budaya, analisis usahatani padi sawah di Kabupaten Siak menunjukkan kategori cukup berkelanjutan untuk Kecamatan Bunga Raya (56,70\%), Sabak Auh $(50,80 \%)$ dan Sungai Mandau $(51,10 \%)$ serta kurang berkelanjutan untuk Kecamatan Sungai apit $(47,70 \%)$. Atribut sosial budaya yang mempunyai sensitifitas terhadap keberlanjutan usahatani padi sawah dimasa yang akan datang untuk empat kecamatan adalah mengikuti pelatihan/ penyuluhan. Motivasi bertani hanya sensitif untuk Kecamatan Bunga Raya, status kepemilikan lahan memberikan sensitivitas pada Kecamatan Sabak Auh, Sungai Apit dan Sungai Mandau sementara umur dan pendidikan petani hanya sensitif untuk Kecamatan Sungai Apit.

\section{UCAPAN TERIMA KASIH}

Terimakasih saya ucapkan kepada Tuhan Yang Maha Esa atas berkat yang diberikan kepada saya. Terimakasih kepada semua pihak yang telah membantu baik material maupun non material demi mendukung saya dalam penelitian ini

\section{DAFTAR PUSTAKA}

Abdollahzadeh, G. Sharifzadeh, MS. Damalas, CA. 2015. Perceptions of the beneficial and harmful effects of pesticides among Iranian rice farmers influence the adoption of biological control. Crop Protection. 75:124-131.

Alder J, TJ, Pitcher, D. Preikshot, K. Kaschner and B. Feriss. 2000. How good is good? A. Rapid Appraisal tecknique for evaluation of the sustainability status of fisheries of the north Atlantic. In Pauly and Pitcher (eds). Methods forevaluationg the impacts of fisheries on the north atlantic ecosystem. Fisheries Center Research Reports. 8(2):136-182. 
Andayani, SA. Sanira. 2015. Pendapatan Usahatani Padi Sawah Berdasarkan Penerapan Sekolah Lapang Pengelolaan Tanaman Terpadu. Jurnal Ilmu Pertanian dan Peternakan. 3(2):42-29

Dewi, MM. Utami, BW. Ihsaniyati, H. 2016. Motivasi Petani Berusahatani Padi (Kasus Di Desa Gunung Kecamatan Simo Kabupaten Boyolali). Jurnal Agrista. 4(3):104-114.

Fauzi, A dan S, Anna. 2005. Pemodelan Sumber Daya Perikanan dan Kelautan (untuk Analisis Kebijakan). Gramedia Pustaka Utama, Jakarta.

Fisheries Centre, 2002. Attributes of Rapfish Analysis for Ecological, Technological, Economic, Social and Ethical Evaluation Fields. Institute of Social and Ethical Evaluation Fields. Institute of Social and Economic Research Press. St John's Canada

Harahap, BH. Ginting, R. dan Hasyim. 2013. Pengaruh Sumber Daya Manusia (SDM) Petani Terhadap Petani Padi Sawah (Studi Kasus: Desa Pematang Setrak, Kec Teluk Mengkudu, Kab Serdang Bedagai). USU. Medan. Journal On Social Economic Of Agriculture and Agribusiness. 2(1):1-15.

Hermawan, H dan H, Andrianyta. 2013. Peran Tambahan Modal Terhadap Pendapatan Usahatani Padi di Kabupaten Blitar dan Ngawi, Jawa Timur. Jurnal Pengkajian dan Pengembangan Teknologi Pertanian, Balai Besar Pengkajia $n$ dan Pengembangan Teknologi Pertanian. Badan Penelitian dan Pengembangan Pertanian. Kementerian Pertanian. Bogor. 16(2):143-158.

Kandaou, EE. 2010. Pengaruh Pelatihan dan Pengembangan Karyawan terhadap Produktivitas Kerja Karyawan (Studi pada PT. Air Manado). Jurnal Penelitian Ilmiah. 6(1):2-4.

Kavanagh, P. 2001. Rapid Appraisal of Fisheries (Rapfish) Project. Rapfish Software Description (for Microsoft Excel). University of British Columbia. Fisheries Centre. Vancouver, Canada. 36 .

Kavanagh, $\mathrm{P}$ and TJ, Pitcher. 2004. Implementing Microsoft Excel Software
For Rapfish: A Technique for The Rapid Appraisal of Fisheries Status. University of British Columbia, Fisheries Centre Research Reports. 12 (2): 75 p.

Liu, F and H, Zhang. 2013. Novel Methods to Assess Environmental, Economic, and Social Sustainability of Main Agricultural Regions in China. Agronomy for Sustainable Development. 16(3):621-633. Mardikanto, T. 2009. Pembangunan Pertanian. Tri Tunggal Tata Fajar. Surakarta.

Mudakir, B. (2011). Produktivitas Lahan dan Distribusi Pendapatan Berdasarkan Status Penguasaan Lahan Pada Usahatani Padi. Jurnal Dinamika Ekonomi Pembangunan. 1(1).

Nababan, MS. Efriyeldi dan Syafruddin, N. 2017. Struktur Komunitas Makrozoobenthos Pada Hutan Mangrove Di Desa Mengkapan Kecamatan Sungai Apit Provinsi Riau. Jurnal Perikanan dan Kelautan. 22(2):24-33.

Nurmalina, R. 2008. Analisis Indeks dan Status Keberlanjutan Sistem Ketersediaan Beras di Beberapa Wilayah Indonesia. Jurnal Argo Ekonomi. 26 (1):47-79.

Okonya, JS and Kroschel, J. 2016. "Farmers' knowledge and perceptions of potato pests and their management in Uganda." Journal of Agriculture and Rural Development in the Tropics and Subtropics. 117(1):87-97.

Pitcher, TJ. DB, Preikshot. 2001. Rapfish: A Rapid Appraisal Technique to Evaluate the Sustainability Status of Fisheries. Fisheries Research. 49(3): 255-270.

Rukka, H dan Wahab, A. 2013. FaktorFaktor yang Mempengaruhi Motivasi Petani dalam Pelaksanaan Kegiatan P2BN DI Kecamatan Barru, Kabupaten Barru. Jurnal Agrisistem. 1 (9) : 46-56.

Ryan, T. 2013. Sample Size Determination and Power. John Wiley and Sons.

Serageldin, I and Steer, A. 1994. Making Development Sustainable : From Consept to Action Enviromentally Sustainable Development Occasional Paper series No. 2. The Word Bank. Washinton D.C.

Shinta, A. 2011. Manajemen Pemasaran. Malang: UB Press. 
Sitorus, SRP. 2004. Pengembangan Sumberdaya Lahan Berkelanjutan. Edisi ke-3. Bogor: Laboratorium Perencanaan Pengembangan Sumberdaya Lahan, Jurusan Tanah, Fakultas Pertanian, Institut Pertanian Bogor.

Sunaryo. 2006. Hubungan Karakteristik Petani Dengan Respon Petani Terhadap Penggunaan Pupuk Organik Pada Padi Sawah. Jurnal Agrisistem. 2 (1). Sekolah Tinggi Penyuluhan Pertanian

Suryana, A. 2005. Pembangunan Pertanian Berkelanjutan Andalan Pembangunan Nasional. Makalah pada Seminar Sistem Pertanian Berkelanjutan untuk Mendukung Pembangunan Nasional. 15 Februari 2005. Universitas Sebelas Maret Solo.
Tesfamichael, D dan TJ, Pitcher. 2006. Multidisciplinary Evaluation of the Sustainability of Red Sea Fisheries Using Rapfish. Fisheries Research 78: 227-235.

Timprasert, S. Datta, A and Ranamukhaarachchi, S. 2014. Factors Determining Adoption of Integrated Pest Management by Vegetable Growers in Nakhon Ratchasima Province, Thailand. Crop Protection. 62:32-39.

Vildan, S. Nizamettin, B and Abdulkadir, C. 2009. Effect Of Formal Education And Tranining On Farmers Income. European Journal of Social Sciences. 7(3):52-62.

Wildemuth B. M., 2009. Application of Social Research Methods to Question in Informan and Library Science. Grennwood Publishing Group, London. 